\title{
PERBANDINGAN MODEL PEMBELAJARAN KOOPERATIF TIPE STUDENT TEAMS ACHIEVEMENT DIVISION (STAD) DENGAN METODE DISKUSI KELAS X SMA NEGERI 1 MODEL MUARA BELITI TAHUN PELAJARAN 2018/2019
}

\author{
Neli Yuliani ${ }^{1}$, Ahmad Amin ${ }^{2}$,Wahyu Arini ${ }^{3}$ \\ ${ }^{1}$ Mahasiswa Program Studi Pendidikan Fisika STKIP-PGRI LLG, \\ ${ }^{2}$ Dosen Program Studi Pendidikan Fisika \\ ${ }^{3}$ Dosen Program Studi Pendidikan Fisika \\ Email: neliyuliani094@gmail.com
}

\begin{abstract}
This study aims to find out the Comparison of Learning Outcomes Between Students' Physics Cooperative Learning Model Type Student Teams Achievement Division (STAD) with Class X Discussion Method 1 Model Muara Beliti 1 High School 2018/2019 Academic Year. The problem in this study is whether there is a comparison of Student Physics Learning Outcomes Between Cooperative Learning Model Student Tesms Achievement Division (STAD) model and Discussion Method in Class X Model Muara Beliti 1 High School 2018/2019 Academic Year?. The type of research used is quantitative in the form of experimental research methods conducted by comparing the experimental group I and the experimental group II design of this study pre-test post-test. As a population of all class X students of SMA Negeri 1 Model Muara Beliti Academic Year 2018/2019, which consisted of 236 students consisting of 7 classes. Sampling was done randomly and as a sample of experimental class I class X.IPA.1, and as a class experiment II class X.IPA.2. Data collection is done by test techniques, namely pre-test and post-test. Then the collected data was analyzed using the $t$-test, based on the results of the $t$-test analysis with a real level of $\alpha=0.05$, obtained tcount $>t$ table $(2.20>2.00)$, so it can be concluded that the results of student physics learning using Cooperative Learning Model Student Tesms Achievement Division (STAD) type is higher than the discussion method in Class X of Model Muara Beliti 1 High School in Academic Year2018/2019.
\end{abstract}

\begin{abstract}
Abstrak: Penelitian ini bertujuan untuk mengetahui Perbandingan Hasil Belajar Fisika Siswa Antara Model Pembelajaran Kooperatif Tipe Student Tesms Achievement Division (STAD) dengan Metode Diskusi Kelas X SMA Negeri 1 Model Muara Beliti Tahun Pelajaran 2018/2019. Masalah dalam penelitian ini adalah apakah ada perbandingan Hasil Belajar Fisika Siswa Antara model pembelajaran Kooperatif Tipe Student Tesms Achievement Division (STAD) dengan Metode Diskusi di Kelas X SMA Negeri 1 Model Muara Beliti Tahun Pelajaran 2018/2019?. Jenis Penelitian yang digunakan berbentuk kuantitatif dengan metode penelitian eksperimen yang dilakukan dengan membandingkan kelompok eksperimen I dan kelompok eksperimen II desain penelitian ini pre-test post-test. Sebagai populasi seluruh siswa kelas X SMA Negeri 1 Model Muara Beliti Tahun Pelajaran 2018/2019, yang terdiri dari 236 siswa yang terdiri dari 7 kelas.pengambilan sempel dilakukan secara acak dan sebagai sampel kelas eksperimen I kelas X.IPA.1, dan sebagai kelas eksperimen II kelas X.IPA.2. Pengumpulan data dilakukan dengan teknik tes, yaitu pre-test dan post-test. Kemudin data yang terkumpul dianalisis menggunakan uji-t, berdasarkan hasil analisis uji-t dengan taraf nyata sebesar $\alpha=0,05$, diperoleh $t_{\text {hitung }}>t_{\text {tabel }}(2,20>2,00)$, sehingga dapat disimpulkan bahwa hasil belajar fisika siswa dengan menggunakan Model Pembelajaran Kooperatif Tipe Student Tesms Achievement Division (STAD) lebih tinggi dari pada metode diskusi di Kelas X SMA Negeri 1 Model Muara Beliti Tahun Pelajaran 2018/2019.
\end{abstract}

(C) 2019 Physics Education Department, STKIP PGRI Lubuklinggau, Indonesia

Kata Kunci:Perbandingan Hasil Belajar, Student Tesms Achievement Division (STAD) denan Metode Diskusi.

\section{PENDAHULUAN}

Pendidikan adalah usaha yang

dilakukan dengan sengaja dan sistematis untuk memotivasi, membina, membantu, serta membimbing seseorang untuk mengembangkan segala potensinya 
sehingga ia mencapai kualitas dari yang lebih baik. Inti pendidikan adalah usaha pendewasaan manusia seutuhnya (lahir dan batin), baik oleh dirinya sendiri maupun orang lain, dalam arti tuntutan agar anak didik memiliki kemerdekaan berpikir, merasa, berbicara, dan bertindak serta percaya diri dengan penuh rasa tanggung jawab dalam setiap tindakan dan perilaku sehari-hari Basri (Tatang S, 2012:14).

Berdasarkan penjelasan di atas, dapat disimpulkan bahwa pendidikan adalah usaha sadar dan terencana untuk mewujudkan suasana belajar agar peserta didik dan keterampilan yang diperlukan dirinya. Jadi, disini pendidikan diharapkan dapat mengembangkan kemampuan yang dimiliki peserta didik, yaitu kemampuan berpikir dan kemampuan berprilaku.

Melalui proses pendidikan diharapkan siswa dapat tumbuh dan berkembang menjadi lebih baik.Guru sebagai tenaga pendidik mempunyai tanggung jawab yang besar terhadap minat belajar siswa dengan tujuan untuk meningkatkan kualitas pendidik. Walaupun saat ini disediakannya gedung sekolah serta sarana belajar yang lengkap, dengan harapan supaya siswa dapat belajar dengan semangat. Tetapi semua ini akan sia-sia jika siswa tidak ada minat atau motivasi untuk belajar.

Oleh karena itu, sebagai tenaga pendidik sekaligus sebagai pembimbing, guru harus semaksimal mungkin untuk dapat menciptakan suasana pembelajaran yang menarik dan menyenangkan. Salah satunya dengan memilih model pembelajaran yang tepat yang di dalam proses pembelajarannya siswa tersebut dituntut untuk lebih aktif dan kreatif sehingga dapat membangun pengetahuan dan pemahamannya sendiri.

Berdasarkan hasil observasi awal peneliti dengan ibu Maulidinah guru fisika SMA Negeri 1 Model Muara Beliti, menunjukan bahwa masih rendahnya hasil belajar siswa. Hal ini dibuktikan peneliti berdasarkan nilai ulangan harian siswa semester dua tahun pelajaran 2018/2019. Nilai rata-rata siswa adalah 65 , sedangkan kriteria ketuntasan minimum (KKM) yang terdapat disekolah tersebut adalah 65 . Kemudian persentase jumlah siswa yang tuntas sebesar $40 \%$ dan yang belum tuntas $60 \%$ dari 236 jumlah siswa. Kenyataan ini menunjukan masih rendahnya pemahaman siswa terhadap materi pembelajaran fisika.

Berdasarkan pemikiran diatas, maka penulis tertarik melakukan penelitian dengan judul "Perbandingan Model Pembelajaran Kooperatif Tipe Student 
Teams Achievement Division (STAD) dengan metode diskusi Kelas X SMA Negeri 1 Model Muara Beliti Tahun Pelajaran 2018/2019”.

\section{KAJIAN TEORITIS}

1. Pengertian Model Pembelajaran

Joyce dan Weil (Rusman, 2011:133), berpendapat bahwa model pembelajaran adalah suatu rencana atau pola yang dapat digunakan untuk membentuk kurikulum (rencana pembelajaran jangka panjang), merencanakan bahan-bahan pembelajaran, dan mambimbing pembelajaran di kelas atau yang lain. Model pembelajaran dapat dijadikan pola pilihan, artinya para guru boleh memilih model pembelajaran yang sesuai dan efisien untuk mencapai tujuan pendidikan. Model pembelajaran adalah suatu pola atau kerangka pembelajaran yang menggambarkan langka-langka dari kegiatan awal sampai kegiatan akhir pembelajaran. Dengan demikian pemilihan model pembelajaran yang sesuai dengan peningkatan hasil belajar dan pemahaman siswa terhadap materi, serta guru akan merasakan adanya kemudahan di dalam pelaksanaan pembelajaran di kelas. Sehingga tujuan pembelajaran dapat tercapai dengan tuntas sesuai harapan.
2. Pengertian Model Pembelajaran Kooperatif

Menurut Esminarto dkk (2016:17), menyatakan bahwa pembelajaran kooperatif merupakan salah satu pembelajaran yang didasarkan pada paham konstruktivisme. Pada pembelajaran kooperatif siswa percaya bahwa keberhasilan mereka akan tercapai jika dan hanya jika setiap anggota kelompoknya berhasil. Slavin (dalam Sukowati dkk, 2016:18), yang menyatakan In cooperative learning methods, students work together in four member teams to master material initially presented by the teacher. Hal ini berarti cooperative learning atau pembelajaran cooperative adalah suatu model pembelajaran dimana sistem belajar dan bekerja kelompok-kelompok kecil berjumlah 4-6 orang secara kolaboratif sehingga dapat merangsang peserta didik lebih bergairah dalam belajar. Sehingga dapat dikatakan bahwa pembelajaran cooperative adalah cara belajar dalam bentuk kelompok-kelompok kecil yang saling bekerjasama dan diarahkan oleh guru untuk mencapai tujuan pembelajaran yang diharapkan.

3. Pengertian Model Pembelajaran KooperatifTipe Student Teams Achievement Division (STAD). 
Menurut Trianto (Gummay dkk 2016:40), model pembelajaran kooperatif tipe Student Teams Achievement Division $(S T A D)$ ini merupakan salah satu tipe dari 2 model pembelajaran kooperatif dengan menggunakan kelompok-kelompok kecil dengan jumlah anggota kelompok 4-5 orang siswa heterogen. Diawali dengan penyampaian tujuan pembelajaran, penyampaian materi, kegiatan kelompok, kuis, dan penghargaan kelompok. Sedangkan menurut Isjoni (2010:74), model pembelajaran kooperatif tipe Student Teams Achievement Division (STAD) pembelajaran merupakan salah satu tipe kooperatif yang menekankan pembelajaran pada adanya aktivitas dan interaksi diantara siswa untuk saling memotivasi dan saling membantu dalam menguasai materi pelajaran guna mencapai prestasi yang maksimal.Simarmata (2014:174), Model pembelajaran kooperatif tipe STAD yaitu model pembelajaran kooperatif yang terdiri dari kelompok belajar siswa yang beranggotakan empat atau lima orang siswa yang merupakan campuran dari kemampuan akademik yang berbeda. Ciri-ciri yang penting dalam model pembelajaran kooperatif tipe STAD adalah adanya penghargaan kepada kelompok atas prestasi kelompok. Penghargaan kelompok penting untuk meningkatkan motifasi belajar peserta didik.

4. Fase-Fase ModelStudent Teams Achievement Division (STAD).

Menurut Edi, dkk (Gummay dkk, 2016:41), langkah-langkah model pembelajaran kooperatif tipe Student Teams Achievement Division (STAD) sebagai berikut:

1. Guru menyampaikan semua tujuan pembelajaran yang ingin dicapai pada pembelajaran tersebut dan memotivasi siswa belajar.

2. Guru menyajikan informasi kepada siswa baik dengan peragaan atau teks.

3. Guru menjelaskan pada siswa bagaimana caranya membentuk kelompok belajar dan membantu setiap kelompok agar melakukan transisi yang efisien.

4. Guru membimbing kelompokkelompok belajar pada saat mereka mengerjakan tugas.

5. Guru mengevaluasi hasil belajar tentang materi yang telah dipelajari atau masing-masing kelompok mempresentasikan hasil kerjanya.

6. Guru mencari cara-cara untuk menghargai baik upaya maupun hasil belajar individu dan kelompok. 
Menurut Trianto (Gummay dkk,2016:40), langkah-langkah model pembelajaran kooperatif tipe Student Teams Achievement Division (STAD) terdiri dari enam fase, yang disajikan pada

Tabel 1. Langkah-langkah model pembelajaran kooperatif tipe Student Teams Achievement Division (STAD)

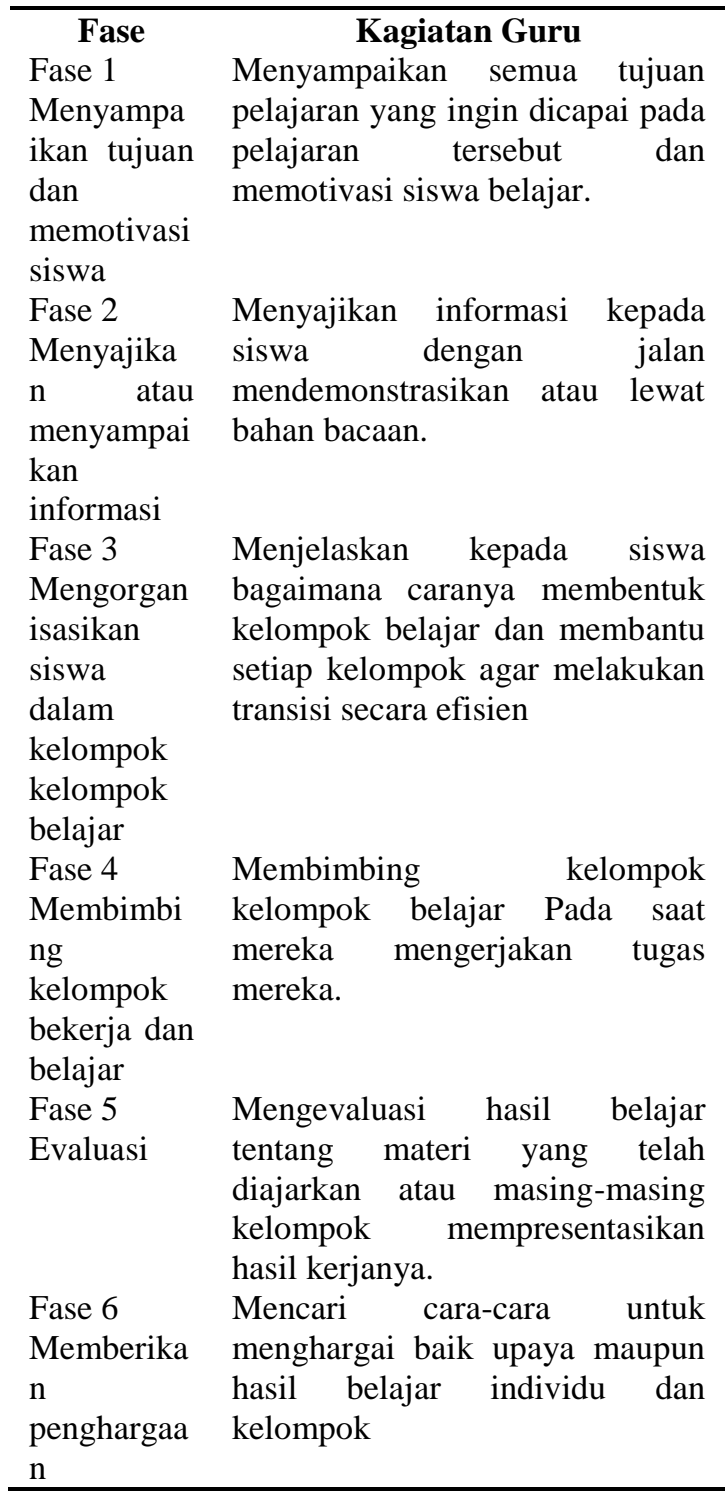

Langkah-langkah penerapan dalam model pembelajaran kooperatif tipe STAD yang diterapkan dalam penelitian ini adalah 6 langkah sebagai berikut: (1) pembagian kelompok, (2) penyampaian

materi, (3) diskusi kelompok,

pemberian kuis /pertanyaan,

penyimpulan, (6) pemberian penghargaan Wibowo (Esminarto dkk, 2016:19).

5. Peningkatan Skor Individu dan Penghargaan Kelompok

Model pembelajaran kooperatif tipe STAD yang meliputi presentasi kelas, belajar kelompok, kuis, peningkatan skor individu, dan penghargaan kelompok. Peningkatan skor skor menurut Slavin (Trianto, 2009:71).

Tabel 2. Perhitungan Skor Peningkataan Individu.

\begin{tabular}{clc}
\hline No & \multicolumn{1}{c}{ Kriteria } & \multicolumn{1}{c}{$\begin{array}{c}\text { Skor } \\
\text { Peningkata } \\
\text { n }\end{array}$} \\
\hline $\mathbf{1}$ & $\begin{array}{l}\text { Lebih dari 10 poin di bawah } \\
\text { skor awal }\end{array}$ & 5 poin \\
$\mathbf{2}$ & $\begin{array}{l}\text { 10 poin di bawah sampai } 1 \\
\text { poin di bawah skor awal }\end{array}$ & 10 poin \\
$\mathbf{3}$ & $\begin{array}{l}\text { Skor dasar sampai 10 poin di } \\
\text { atas skor awal }\end{array}$ & 20 poin \\
$\mathbf{4}$ & $\begin{array}{l}\text { Lebih dari 10 poin di atas } \\
\text { skor awal }\end{array}$ & 30 poin \\
$\mathbf{5}$ & $\begin{array}{l}\text { Nilai sempurna (tenpa } \\
\text { memperhatikan skor awal) }\end{array}$ & 30 poin \\
\hline Penghargaan kelompok menurut & meman
\end{tabular}

Trianto (2009:71), ada tiga tingkat atau kriteria skor tim rata-rata, seperti pada

Tabel 3.Kriteria Penghargaan Prestasi Tim

\begin{tabular}{cc}
\hline $\begin{array}{c}\text { Rata-rata poin } \\
\text { kelompok }\end{array}$ & Kriteria penghargaan \\
\hline $\mathbf{0} \leq \mathbf{x} \leq \mathbf{5}$ & - \\
$\mathbf{5} \leq \mathbf{x} \leq \mathbf{1 5}$ & Tim baik (Good teams) \\
$\mathbf{1 5} \leq \mathbf{x} \leq \mathbf{2 5}$ & Tim hebat (Great teams) \\
$\mathbf{2 5} \leq \mathbf{x} \leq \mathbf{3 0}$ & Tim super (Super teams) \\
\hline
\end{tabular}

2. Kelebihan Dan Kelemahan Student Teams Achievement Division (STAD) 
a. Kelebihan Student Teams Achievement Division(STAD)

Menurut Rusman (Esminarto dkk, 2016:20), berdasarkan karakteristiknya ialah: setiap siswa memiliki kesempatan untuk memberikan kontribusi yang substansial kepada kelompoknya, dan posisi anggota kelompok adalah setara, menggalakkan interaksi secara aktif dan positif dan kerjasama anggota kelompok menjadi lebih baik, membantu siswa untuk memperoleh hubungan pertemanan lintas rasial yang lebih banyak, siswa memiliki dua bentuk tanggung jawab belajar. yaitu belajar untuk dirinya sendiri dan membantu sesama anggota kelompok untuk belajar.

Menurut Isjoni (2010), Kelebihan STAD adalah melatih siswa dalam mengembangkan aspek kecakapan sosial di samping kecakapan kognitif dan peran guru juga menjadi lebih aktif dan lebih terfokus sebagai fasilitator, mediator, motivator dan evaluator.

b. Kelemahan Student Teams

Achievement Division (STAD)

Menurut Khusna (Esminarto dkk, 2016:21), kelemahan STAD adalah: pembelajaran menggunakan model ini membutuhkan waktu yang relatif lama, dengan memperhatikan tiga langkah STAD yang menguras waktu seperti penyajian materi dari guru, kerja kelompok dan tes individual/kuis, karena rata-rata jumlah siswa di dalam kelas adalah 45 orang, maka guru kurang maksimal dalam mengamati belajar kelompok secara bergantian, guru dituntut bekerja cepat dalam menyelesaikan tugas-tugas yang berkaitan dengan pembelajaran yang telah dilakukan.

\section{Pengertian Belajar}

Belajar merupakan aktivitas manusia yang sangat vital dan secara terusmenerus akan dilakukan selama manusia tersebut masih hidup. Manusia tidak mampu hidup sebagai manusia jika ia tidak dididik atau diajar oleh manusia lainnya (Thobroni, 2015:15).

Belajar merupakan suatu aktivitas yang dapat dilakukan secara psikologis maupun secara fisiologis. Aktivitas yang bersifat psikologis yaitu aktivitas yang merupakan proses mental, misalnya aktivitas berfikir, memahami, menyimpulkan, menyimak, menelaah, membandingkan, membedakan, mengungkapkan, menganalisis dan sebagainya (Rusman, 2012:85).

Menurut Iskandarwassid (Muthoharoh, 2017:34), hasil belajar adalah yang diperoleh peserta didik setelah mengikuti suatu materi tertentu dan mata pelajaran yang berupa data kuantitatif maupun kualitatif. 
Wasliman (Ahmad Susanto, 2013:12), hasil belajar yang dicapai oleh peserta didik merupakan hasil interaksi antara berbagai faktor yang memengaruhi, baik faktor internal maupun eksternal:

a) Faktor internal; faktor internal merupakan faktor yang bersumber dari dalam diri peserta didik, yang memengaruhi kemampuan belajarnya.

b) Faktor eksternal; faktor yang berasal dari luar diri peserta didik yang memengaruhi hasil belajar yaitu keluarga, sekolah dan masyarakat. Keadaan keluarga berpengaruh terhadap hasil belajar sisiwa.

Bloom (dalam Rusman, 2013:125), menjelaskan bahwa domain kognitif terdiri dari enam kategori yaitu:

a. Pengetahuan (Knowledge) $\left(C_{1}\right)$, yaitu jenjang kemampuan yang menuntut peserta didik untuk dapat mengenali atau mengetahui adanya konsep, prinsip, fakta atau istilah tanpa harus mengerti atau dapat menggunakannya.

b. Pemahaman (comprehension) $\left(C_{2}\right)$ yaitu jenjang kemampuan yang menuntut peserta didik untuk memahami atau mengerti tentang materi pelajaran yang disampaikan guru dan dapat memanfaatkannya tanpa harus menghubungkannya dengan hal-hal lain. c. Penerapan (application) $\left(C_{3}\right)$ yaitu jenjang kemampuan yang menuntut peserta didik untuk menggunakan ideide umum, tata cara ataupun metode, prinsip, dan teori-teori dalam situasi baru dan konkret.

d. Analisis (analysis) $\left(C_{4}\right)$ yaitu jenjang kemampuan yang menuntut peserta didik untuk menguraikan suatu situasi atau keadaan tertentu ke dalam unsur-unsur atau komponen pembentukannya.

e. Sintesis (synthesis) $\left(C_{5}\right)$ yaitu jenjang kemampuan yang menuntut peserta didik untuk menghasilkan sesuatu yang baru dengan cara menggabungkan berbagai faktor.

f. Evaluasi (evaluation) $\left(C_{6}\right)$ yaitu jenjang kemampuan yang menuntut peserta didik untuk dapat mengevaluasi suatu situasi, keadaan, pernyataan atau konsep berdasarkan kriteria tertentu.

\section{METODOLOGI PENELITIAN}

Jenis penelitian yang digunakan ini adalah penelitian kuantitatif dengan metode eksperimen. Desain penelitian yang digunakan berbentuk pre-test dan post-test Control Group Design dapat dilihat pada 
Tabel 4. Pre-test-posttest Control Group Design

\begin{tabular}{cccc}
\hline $\begin{array}{c}\text { Gro } \\
\text { up }\end{array}$ & Pre-test & Treatment & Post-test \\
\hline $\mathrm{X}_{1}$ & $\mathrm{O}_{1}$ & $\mathrm{X}$ & $\mathrm{O}_{2}$ \\
$\mathrm{X}_{2}$ & $\mathrm{O}_{3}$ & - & $\mathrm{O}_{4}$ \\
\hline
\end{tabular}

Penelitian ini dilaksanakan di SMA

Negeri 1 Model Muara Beliti sebagai tempat yang menjadi fokus penelitian. Penelitian ini dilaksanakan pada tanggal 10 September 2019.

Sampel penelitian ini adalah kelas X.1 yang berjumlah 32 siswa sebagai kelas eksperimen dan kelas X.2 yang berjumlah 32 siswa sebagai kelas kontrol. Untuk mengetahui butir soal, maka rumus yang digunakan adalah korelasi product moment:

$\mathrm{r}_{\mathrm{xy}}=\frac{N \sum X Y-\left(\sum X\right)\left(\sum Y\right)}{\sqrt{\left\{N \sum X^{2}-\left(\sum X\right)^{2}\right\}\left\{N \sum Y^{2}-\left(\sum Y\right)^{2}\right\}}}$

keterangan :

$\mathrm{r}_{\mathrm{xy}}$ : Koefisien korelasi

$\mathrm{N}$ : Jumlah siswa uji coba

$X$ : Skor tiap butir soal

Y : Skor total tiap siswa uji coba

Tabel 5. Kriteria Validitas

\begin{tabular}{cc}
\hline Kriteria validitas & Kategori \\
\hline$r_{\mathrm{xy}} \leq 0,00$ & Tidak valid \\
$0,00<\mathrm{r}_{\mathrm{xy}} \leq 0,20$ & sangat rendah \\
$0,20<\mathrm{r}_{\mathrm{xy}} \leq 0,40$ & Rendah \\
$0,40<\mathrm{r}_{\mathrm{xy}} \leq 0,60$ & Sedang \\
$0,60<\mathrm{r}_{\mathrm{xy}} \leq 0,80$ & Tinggi \\
$0,80<\mathrm{r}_{\mathrm{xy}} \leq 1,00$ & sangat tinggi \\
\hline
\end{tabular}

Tes yang digunakan adalah tes uraian, maka rumus untuk menghitung reliabilitas soal bentuk uraian menggunakan rumus alpha cronbach yaitu:

$\mathrm{r}_{11}=\left(\frac{k}{k-1}\right)\left(1-\frac{\sum \sigma_{b}^{2}}{\sigma_{t}^{2}}\right)$ (Arikunto,

2010:239)

Keterangan:

$\mathrm{r}_{11}=$ reliabilitas instrument $\mathrm{k}$ =banyaknya butir pertanyaan atau banyaknya soal $\sum \sigma_{b}^{2}=$ jumlah varians butir $\sigma_{t}^{2}=$ varians total

Tabel 6. Klasifikasi Reliabilitas

\begin{tabular}{cc}
\hline Besarnya Nilai $\mathrm{r}_{11}$ & Interval \\
\hline $\mathrm{r}_{11} \leq 0,20$ & sangat rendah \\
$0,20<\mathrm{r}_{11} \leq 0,40$ & Rendah \\
$0,40<\mathrm{r}_{11} \leq 0,60$ & Cukup \\
$0,60<\mathrm{r}_{11} \leq 0,80$ & Tinggi \\
$0,80<\mathrm{r}_{11} \leq 1,00$ & sangat tinggi \\
\hline
\end{tabular}

Daya pembeda ditentukan dengan

rumus sebagai berikut:

$D P=\frac{B a}{J a}-\frac{B b}{J b} \quad$ (Bagiyono, 2017:4)

Keterangan:

$D P=$ Indeks daya pembeda

$B_{a}=$ Jumlah skor kelompok atas

$B_{b}=$ Jumlah skor kelompok bawah

$J_{a}=$ Jumlah skor ideal kelompok atas

$J_{b}=$ Jumlah skor ideal kelompok bawah

Tabel 7. Klasifikasi Daya Pembeda

\begin{tabular}{cc}
\hline nilai Daya & Kategori \\
Pembeda & \\
\hline $\mathrm{D} \leq 0$ & Rendah Sekali \\
$0<\mathrm{D} \leq 0,2$ & Rendah \\
$0,2<\mathrm{D} \leq 0,4$ & Sedang \\
$0,4<\mathrm{D} \leq 0,7$ & Tinggi \\
$0,7<\mathrm{D} \leq 1$ & Sangat Tinggi \\
\hline
\end{tabular}

Tingkat kesukaran dalam butir tes adalah sebagai berikut:

$D=\frac{B a+B b}{J a+J_{B}}$ (Bagiyono, 2017:03)

Keterangan:

$D=$ Indeks Kesukaran

$B a=$ Jumlah skor kelompok atas

$B_{b}=$ Jumlah skor kelompok bawah

$J_{a}=$ Jumlah skor ideal kelompok atas

$J_{b}=$ Jumlah skor ideal kelompok bawa

Tabel 8. Klasifikasi Tingkat Kesukaran

\begin{tabular}{cc}
\hline Besarnya Nilai & Kategori Tingkat Kesukaran \\
\hline 0 & Sangat Sukar \\
$0<\mathrm{P} \leq 0,3$ & Sukar \\
\hline
\end{tabular}




\begin{tabular}{cc}
\hline $0,3<\mathrm{P} \leq 0,7$ & Sedang \\
$0,7<\mathrm{P}<1$ & Mudah \\
1 & Sangat Mudah \\
\hline
\end{tabular}

Dalam uji kesamaan rata-rata ini jika kedua data berdistribusi normal dan homogen, maka uji statistik yang digunakan yaitu $u j i-t$ dengan rumus:

$t=\frac{\overline{x_{1}}-\overline{x_{2}}}{s \sqrt{\frac{1}{n_{1}}+\frac{1}{n_{2}}}}$ dan $s=\sqrt{\frac{\left(n_{1}-1\right) s_{1}^{2}+\left(n_{2}-1\right) s_{2}^{2}}{n_{1}+n_{2}-2}}$

(Sugiyono, 2012:138)

Keterangan:

$\bar{x}_{1}=$ Skor rata-rata kelas eksperimen

$\bar{x}_{2}=$ Skor rata-rata kelas kontrol

$n_{1}=$ Jumlah siswa kelas eksperimen

$n_{2}=$ Jumlah siswa kelas kontrol

$S=$ Simpangan baku gabungan dari kedua kelompok

$s_{1}=$ Simpangan baku kelas eksperimen

$s_{2}=$ Simpangan baku kelas kontrol

\section{HASIL DAN PEMBAHASAN}

Penelitian ini dilakukan di SMA

Negeri 1 Model Muara Beliti pada tanggal 10 September sampai dengan 6 oktober 2018. Dalam penelitian ini peneliti menggunakan dua kelas sebagai sampel dari jumlah populasi sebanyak tujuh kelas. Kelas yang dijadikan kelas eksperimen I adalah kelas X.1 dan X.2 sebagai kelas eksperimen II. Kelas X.1 sebagai kelas eksperimen I mendapatkan perlakuan dengan menggunakan model pembelajaran kooperatip tipe Student Teams Achievent Division (STAD), sedangkan kelas X.2 sebagai kelas eksperimen IIl diberikan perlakuan dengan menggunakan model diskusi dalam penyampaian materi.

Pertemuan tatap muka pada penelitian ini sebanyak enam kali pertemuan, dengan rincian satu kali pemberian pretest, empat kali proses pembelajaran dengan menggunakan model pembelajaran kooperatip tipe Student Teams Achievent Division (STAD) dan satu kali pemberian post-test dikelas eksperimen I. Pada kelas eksperimen II, Pertemuan ini sebanyak enam kali pertemuan, dengan rincian satu kali pemberian pre-test, empat kali proses pembelajaran dengan menggunakan model pembelajaran diskusi dan satu kali pemberian post-tes.

a. Deskripsi dan Analisis Data Pre-test

Peneliti memberikan pre-test pada kelas X.2 sebagai kelas eksperimen II, pada tanggal 17 September 2018 dan pretest pada kelas X.1 sebagai kelas eksperimen I dilaksanakan pada tanggal 17 September 2018, untuk mengetahui kemampuan awal siswa kelas eksperimen II dan kelas eksperimen I. Setelah diberikan pembelajaran kedua kelas tersebut akan diberikan pos-test yang dilaksanakan pada tanggal 2 Oktober 2018 kelas eksperimen II dan 2 Oktober 2018 pada kelas eksperimen I. Adapun deskripsi hasil penelitian data tes pre-test di bawah ini: 
Tabel 9. Rekapitulasi data hasil pre-test

\begin{tabular}{ccccc}
\hline No & Kelas & N & $\overline{\boldsymbol{x}}$ & $\mathrm{S}$ \\
\hline 1 & $\mathrm{X}_{1}$ & 32 & 27,68 & 7,97 \\
2 & $\mathrm{X}_{2}$ & 32 & 24,28 & 7,12 \\
\hline
\end{tabular}

Dapat disimpulkan bahwa kemampuan awal siswa kelas eksperimen I dan kelas eksperimen II masih rendah.

b. Deskripsi Akhir Siswa (post-test)

Kemampuan akhir siswa dalam penguasaan materi vektor merupakan hasil belajar siswa setelah mengikuti proses pembelajaran yang telah diberikan perlakuan yang berbeda oleh peneliti. Adapun deskripsi hasil penelitian data tes post-test di bawah ini:

Tabel 10 Rekapitulasi data hasil post-test

\begin{tabular}{ccccc}
\hline No & Kelas & $\mathrm{N}$ & $\overline{\boldsymbol{x}}$ & $\mathrm{S}$ \\
\hline 1 & $\mathrm{X}_{1}$ & 32 & 46,65 & 7,20 \\
2 & $\mathrm{X}_{2}$ & 32 & 42,53 & 7,89 \\
\hline \multicolumn{5}{c}{ Dapat disimpulkan } \\
bahwa & rata-rata
\end{tabular}

nilai kelas eksperimen I lebih besar dari pada kelas eksperimen II.

Perbandingan hasil belajar fisika siswa saat pre-test dan post-test pada kelas eksperimen I dan kelas eksperimen II dapat dilihat pada gambar dibawah ini.

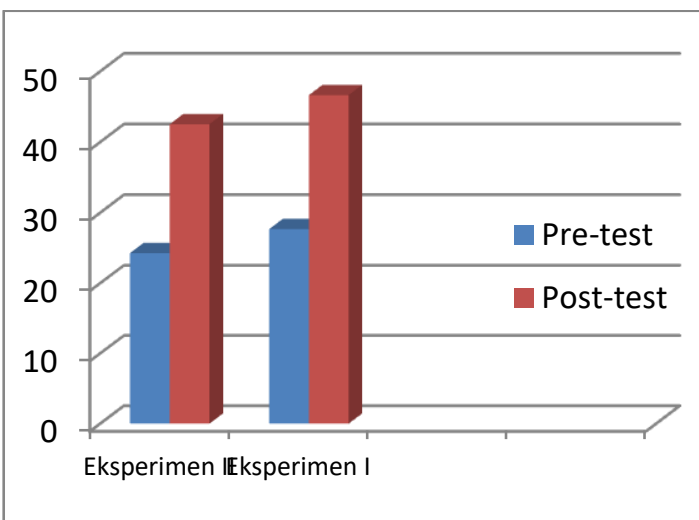

Gambar 1. Skor Rata-rata Pre-test dan Post-test c. Pengujian Hipotesis

Adapun hipotesis statistik dalam penelitian ini adalah ada perbandingan Model Pembelajaran Kooperatif Tipe Student Teams Achievement Division (STAD) dengan metode diskusi Kelas X SMA Negeri 1 Model Muara Beliti Tahun Pelajaran 2018/2019.

1) Uji Normalitas

Uji normalitas digunakan untuk mengetahui apakah data yang didapat berdistribusi normal atau tidak. Berdasarkan perhitungan ststistik menggunakan uji normalitas data adalah uji kecocokan chi kuadrat $\left(x^{2}\right)$ dengan taraf signifikan $\quad \alpha=0,05, \quad$ jika $x_{\text {hitung }}^{2}<x_{\text {tabel }}^{2}$ maka data tersebut dinyatakan berdistribusi normal dapat dilihat pada kurva.

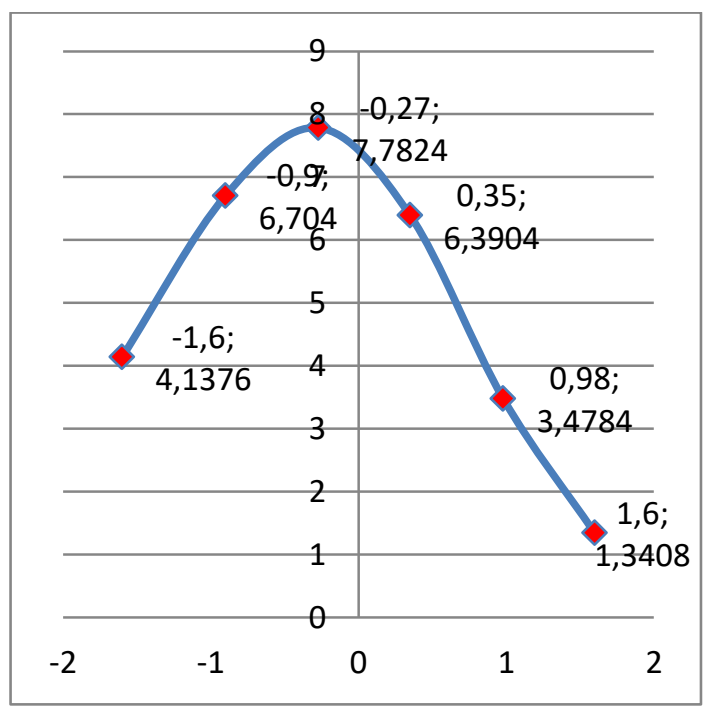

Gambar 2. Kurva Normalitas Pre-Test Kelas Eksperimen 
Rekapitulasi hasil uji normalitas data pre-Test untuk kedua kelompok dapat dilihat pada tabel dibawah ini:

Tabel 11 Hasil Uji Normalitas Pre-Test

\begin{tabular}{ccccccc}
\hline No Kelas & Tes & $\boldsymbol{x}_{\text {hitung }}^{\mathbf{2}}$ & Dk & $\boldsymbol{x}_{\text {tabel }}^{2}$ & kes \\
\hline $\mathbf{1}$ & $\mathrm{X}_{1}$ & Pre-test & 5,93 & 5 & 11,07 & Normal \\
$\mathbf{2}$ & $\mathrm{X}_{2}$ & Pre-test & 13,38 & 5 & 14,06 & Normal
\end{tabular}

Dari data diatas dapat dilihat bahwa $x_{\text {hitung kelas eksperimen I dan kelas }}^{2}$ Eksperimen II kurang dari $x_{\text {tabel }}^{2}$, sehingga kedua kelas tersebut berdistribusi normal.

\section{2) Uji Homogenitas}

Uji homogenitas ini dilakukan untuk mengetahui apakah data pre-test kelas eksperimen dan kelas kontrol memiliki varians yang homogen atau tidak homogen. Rekapitulasi uji homogenitas data pre-test pada keas eksperimen I dan kelas Eksperimen II dapat dilihat pada tabel sebagai berikut:

Tabel 12 Rekapitulasi Hasil Uji Homogenitas Data PreTest

\begin{tabular}{ccccc}
\hline Data & $F_{\text {hitun }}$ & Dk & $F_{\text {tabe }}$ & Ket \\
& $g$ & & $l$ & \\
\hline Pre-test & 1,25 & 62 & 1,84 & Homogen \\
\hline
\end{tabular}

Dari data dia atas dapat dilihat bahwa $F_{\text {hitung }}$ lebih dari $F_{\text {tabel }}$, sehingga diperoleh bahwa kedua varians kelas eksperimen dan kelas kontrol homogen.

3) Uji Kesamaan Dua Rata-rata

Setelah uji normalitas dan uji homogebitas kita lakukan, dan diperoleh kesimpulan bahwa data pre-test pada kelas eksperimen I dan kelas Eksperimen II adalah berdistribusi normal dan homogen, dengan demikian uji kesamaan dua rata-rata menggunakan uji-t.

Kriteria pengujian hipotesis yang digunakan oleh peneliti adalah terima $\mathrm{H}_{\mathrm{o}}$ Jika $\mathrm{t}_{\text {hitung }}<\mathrm{t}_{\text {tabel }}$. Rekapitulasi hasil perhitungan uji kesamaan dua rata-rata dapat dilihat pada tabel sebagai berikut.

Tabel 13 Rekapitulasi Hasil Uji Kesamaan Dua RataRata

\begin{tabular}{cccc}
\hline Data & $\boldsymbol{t}_{\text {hitung }}$ & $\boldsymbol{t}_{\text {tabel }}$ & Ket \\
\hline Pre-test & 1,87 & 2,00 & $\mathrm{H}_{\mathrm{o}}$ diterima \\
\hline
\end{tabular}

Dari tabel diatas dapat dilihat bahwa $t_{\text {hitung }}>t_{\text {tabel }}$ sehingga $\mathrm{H}_{\mathrm{o}}$ ditolak. Dapat diproleh kesimpulan bahwa data pre-test terhadap hasil belajar siswa tidak memiliki perbedaan antara kelas eksperimen dan kelas kontrol.

d. Analisis Inferensial Data Post-Test

1) Uji Normalitas

Uji normalitas ini dilakukan setelah perhitungan rata-rata dan simpangan baku terhadap hasil belajar fisika siswa pada saat post-test baik dikelas eksperimen dan kelas kontrol, dapat dilihat pada kurva.

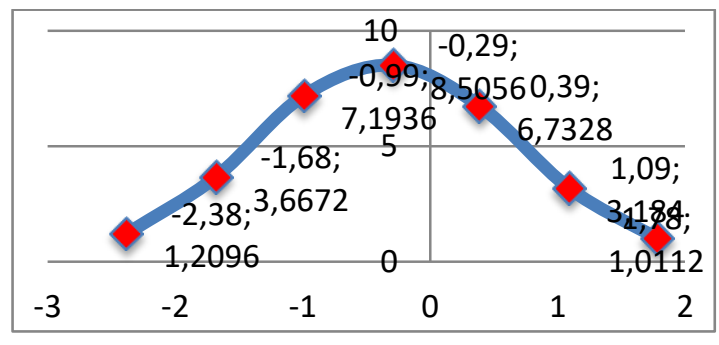

Gambar 3 Kurva Normalitas Post-Test Kelas Eksperimen I 
Rekapitulasi hasil uji normalitas data post-test pada kelas eksperimen dan kelas kontrol dapat dilihat pada tabel.

Tabel 14 Hasil Uji Normalitas Post-Test

\begin{tabular}{ccccccc}
\hline No & Kelas & Tes & $\boldsymbol{x}_{\text {hitung }}^{\mathbf{2}}$ & Dk & $\boldsymbol{x}_{\text {tabel }}^{\mathbf{2}}$ & kes \\
\hline 1 & $\mathrm{X}_{1}$ & Post-test & 3,47 & 5 & 12,59 & Normal
\end{tabular}
\begin{tabular}{lllllll}
2 & $\mathrm{X}_{2}$ & Post-test & 7,93 & 5 & 11,07 & Normal \\
\hline
\end{tabular}

Dari data diatas dapat dilihat bahwa $x_{\text {hitung kelas eksperimen I dan kelas }}^{2}$ Eksperimen II $x_{\text {tabel }}^{2}$, sehingga kedua kelas tersebut berdistribusi normal.

2) Uji Homogenitas

Uji homogenitas ini dilakukan untuk mengetahui apakah data post-test kelas eksperimen I dan kelas Eksperimen II memiliki varians yang homogen atau tidak homogen. Rekapitulasi hasil uji homogenitas data post-test pada kelas eksperimen I dan kelas Eksperimen II dapat dilihat pada tabel.

Tabel 15 Rekapitulasi Hasil Uji Homogenitas Data Post-Test

\begin{tabular}{ccccc}
\hline Data & $F_{\text {hitung }}$ & Dk & $F_{\text {tabel }}$ & Kesimpulsn \\
\hline Pre-test & 1,20 & 62 & 1,84 & Homogen \\
\hline
\end{tabular}

Dari data di atas dapat dilihat bahwa $F_{\text {hitung }}$ kurang dari $F_{\text {tabel }}$, sehingga diperoleh kesimpulan bahwa varians kelas eksperimen I dan kelas Eksperimen I I homogen.

3) Uji Perbedaan Dua Rata-rata

Setelah uji normalitas dan uji homogenitas kita lakukan, dan diperoleh kesimpulan bahwa data post-test pada kelas eksperimen I dan kelas Eksperimen II adalah berdisribusi normal dan homogen. Dengan demikian uji kesamaan data rata-rata menggunakan uji-t.

Kriterian pengujian hipotesis yang digunakan oleh peneliti adalah terima $\mathrm{H}_{\mathrm{o}}$ jika $t_{\text {hitung }}$ kurang dari atau sama $t_{\text {tabel }}$ dan sebaliknya terima $\mathrm{H}_{\mathrm{a}}$ jika $t_{\text {hitung }}$ lebih dari $t_{\text {tabel. }}$ Rekapitulasi hasil perhitungan uji kesamaan dua rata-rata hasil post-test dapat dilihat pada tabel.

Tabel 16 Rekapitulasi Hasil Uji Kesamaan Dua RataRata

\begin{tabular}{cccc}
\hline Data & $t_{\text {hitung }}$ & $t_{\text {tabel }}$ & Kesimpulan \\
\hline Post-test & 2,20 & 2,00 & $\mathrm{H}_{\mathrm{a}}$ diterima \\
\hline
\end{tabular}

Dari tabel diatas dapat diperoleh bahwa terima $\mathrm{H}_{\mathrm{o}}$ karena $t_{\text {hitung }}>t_{\text {tabel }}$, sehingga hipotesis yang diajukan dalam penelitian ini terbukti.

\section{SIMPULAN DAN SARAN}

\section{a. Simpulan}

Berdasarkan hasil penelitian dan pembahasan, diperoleh rata-rata skor tes akhir kelas eksperimen sebesar 46,65 dan kelas kontrol sebesar 42,53. Dapat disimpulkan bahawa ada pengaruh model pembelajaran Kooperatif tipe Student Teams Achievent Division (STAD) terhadap Hasil Belajar Fisika Siswa Kelas X SMA 1 Model Muara Beliti Tahun Pelajaran 2018/2019. 


\section{b. Saran}

Berdasarkan hasil penelitian dan kesimpulan diatas, maka peneliti menyampaika saran-saran sebagai berikut:

1. Siswa, diharapkan agar lebih aktif dalam belajar terutama dalam menyelesaikan soal-soal secara mandiri ataupun berkelompok.

2. Guru, diharapkan dapat memotifasi siswa untuk aktif dan mandiri, bertanggung jawab dan bekerja sama dalam peroses pembelajar berlangsung. Dan meningkatkan interaksi dalam kegiatan belajarsehingga terjalinnya komunikasi yang baik.

3. Model pembelajaran kooperatif tipe Student Teams Achievent Division (STAD), dapat menjadi salah satu alternatif pada pembelajaran fisika agar siswa lebih aktif dan adanya interaksi antara siswa dengan siswa dan guru.

\section{DAFTAR PUSTAKA}

Esminarto, Sukawati, Suryowati, N., Anam, K. 2016. Implementasi Model Stad Dalam Meningkatkan Hasil Belajar Siswa. Jurnal Pendidikan Fisika. Vol. 1 Hal 1623.

Gumay, O. Kodarsih, E. Mulyanto, A. 2016. Pengaruh Model Pembelajaran Kooperatif Tipe
Student Teams Achievement Division (STAD) Terhadap Hasil Belajar Fisika Siswa Kelas X Sma Negeri 2 Muara Beliti Tahun Pelajaran 2015/2016. Jurnal Pendidikan Fisika. Vol. 5 Hal 39 44.

Muthoharoh. 2017. Pengaruh Model Pembelajaran Koopratif "Think Pair Share (TPS)" Terhadap Hasil Belajar Bahasa Inggris. Jurnal Pendidikan. Vol. 2 Hal 33-42.

Rusman 2011.

Model-Model Pembelajaran. Jakarta: Rajawali.

Rusman. 2012. Belajar Dan Pembelajaran Berbasis Komputer. Jakarta: Rajawali Pers.

Rusman, 2013. Belajar Dan Pembelajaran Komputer. Bandung: Alfabeta.

Sugiyono. 2012. Statistik Untuk Penelitian. Bandung : Alfabeta.

Simarmata, U. Pengaruh Model Pembelajaran Kooperatif Tipe STAD Terhadap Hasil Belajar Siswa Pada Materi Listrik Dinamis Di Kelas X Sma. Jurnal Pendidikan Fisika. Vol. 2 Hal 173-180.

Sutrisno, Joko.2015. Pengaruh Model Pembelajaran Koopratif Tipe Student Teams Achievement Division (STAD) Terhadap Hasil Belajar Fisika Siswa Kelas X SMK Negeri Tugumulyo Tahun Pelajaran 2014/2015. Skripsi tidak diterbitkan. Lubuklinggau: jurusan fisika dan ilmu pengatahuan alam STKIP PGRI lubuklinggau.

Sulaeman. 2018. Analisis Pengaruh Kualitas Pelayanan Dan Produk Terhadap Kepuasan Pelanggan Pada PT. Cakrawala Citramega. Jurnal pendidikan. Vol.6 Hal 125145.

Tatang. 2012. Ilmu Pendidikan. Bandung: Pustaka Setia. 
Trianto. 2011. Mendesain Model Pembelajaran Inovatif-Progresif. Jakarta: Kencana.

Thobroni. 2015. Belajar Dan Pembelajaran. Yogyakarta: ArRuzz Media. 